Supplement of Biogeosciences, 18, 393-401, 2021

https://doi.org/10.5194/bg-18-393-2021-supplement

(C) Author(s) 2021. This work is distributed under

the Creative Commons Attribution 4.0 License.

(c) (1)

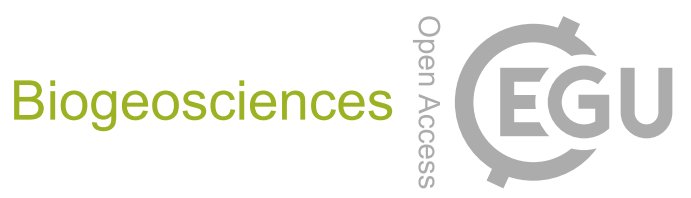

Supplement of

\title{
Carbonic anhydrase is involved in calcification by the benthic foraminifer Amphistegina lessonii
}

Siham de Goeyse et al.

Correspondence to: Siham de Goeyse (siham.de.goeyse@nioz.nl)

The copyright of individual parts of the supplement might differ from the CC BY 4.0 License. 


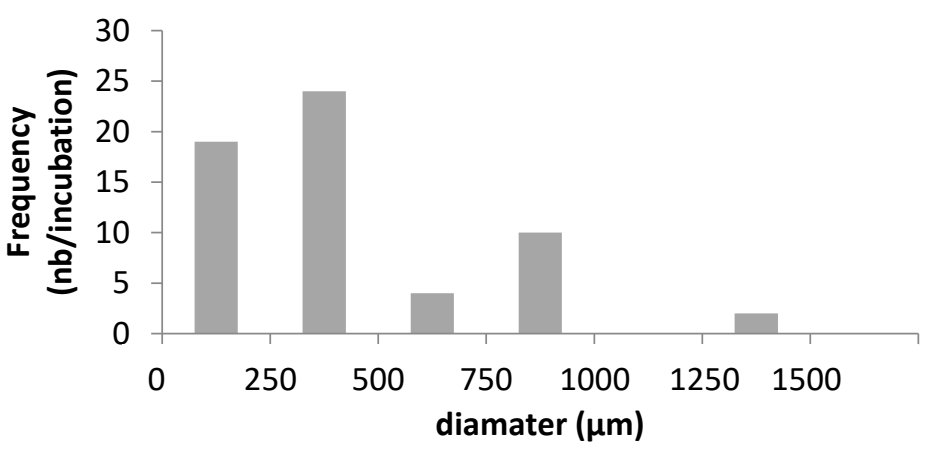

S1: Size distribution of specimens used during the experiment: initial diameter of foraminifera for one replicate
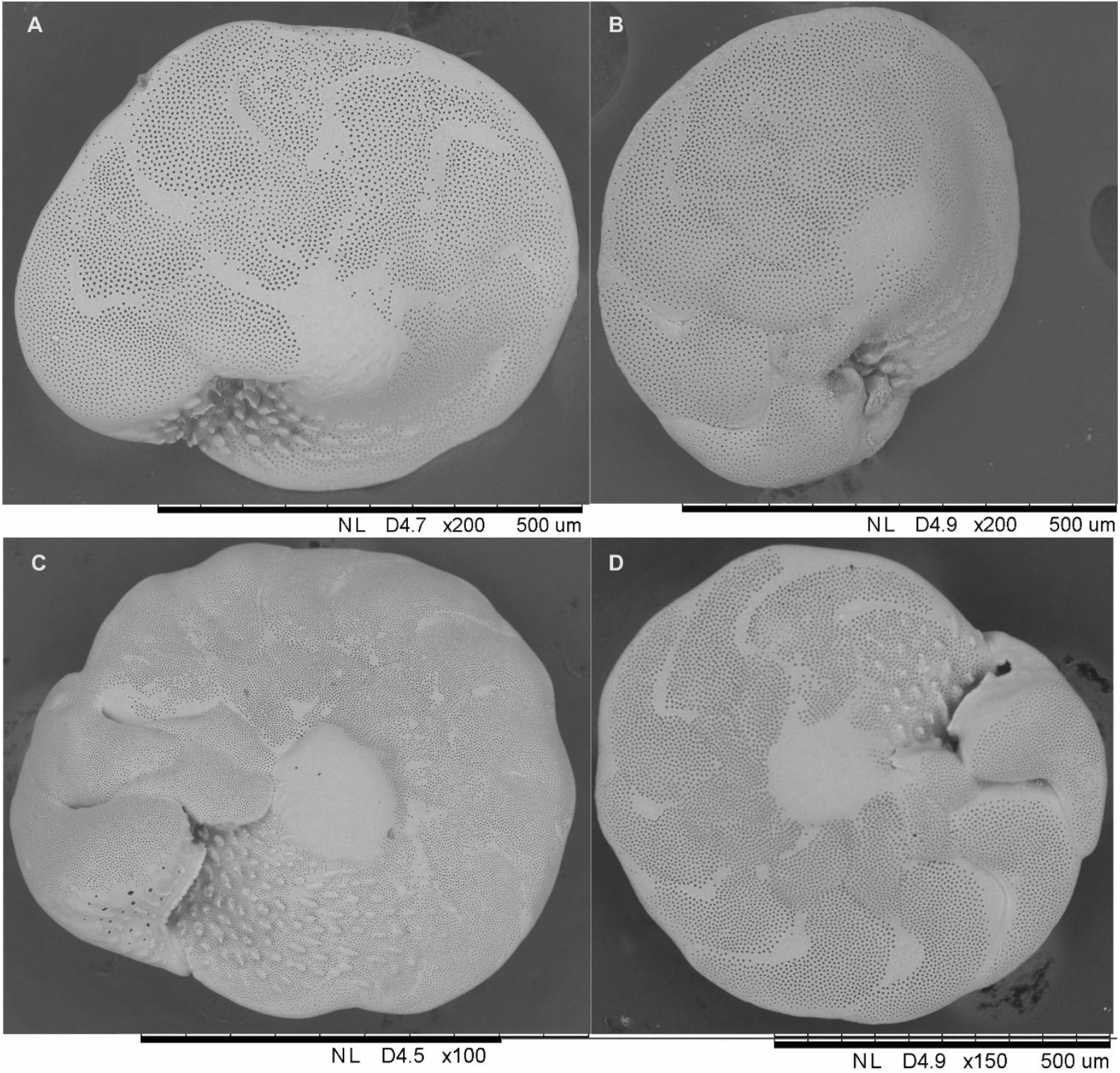

S2: SEM images of foraminifera grown under different conditions (A: DCUM, B: Dark, C: AZ, D: control) 8 